\title{
Jurisprudencia de la Corte Interamericana de Derechos Humanos
}

\author{
James Vértiz Medina ${ }^{1}$ | Universidad Nacional de La Plata \\ Revista Derechos en Acción ISSN 2525-1678/ e-ISSN 2525-1686 \\ Año 4/Nº 12 INVIERNO 2019 (21 junio a 20 septiembre), 496-505 \\ DOI: https://doi.org/10.24215/25251678e316 \\ ORCID: https://orcid.org/0000-0003-2261-1999
}

Corte IDH. Caso Gorigoitía Vs. Argentina. Excepción Preliminar, Fondo, Reparaciones y Costas. Sentencia de 2 de septiembre de 2019. Serie C No. 382

I. Hechos: Los hechos del caso se relacionan con la violación del derecho a recurrir el fallo debido a la inexistencia de un recurso ordinario que permita la revisión integral de la sentencia condenatoria impuesta al agente policial Oscar Raúl Gorigoitía por el delito de homicidio simple en el marco de un proceso penal en la Provincia de Mendoza, Argentina, en 1997.

II. Fondo: El Tribunal de San José, se avocó en el presente a determinar si el Estado argentino es responsable por la violación al derecho a recurrir el fallo ante juez o tribunal superior y al de un recurso judicial efectivo, como resultado de la respuesta de los tribunales internos a los recursos intentados por la defensa del señor Gorigoitía después de su sentencia condenatoria por el delito de homicidio simple.

En el caso en comento, la Corte recordó su jurisprudencia constante sobre sobre el alcance y contenido del artículo 8.2.h) de la Convención, así como a los estándares que deben ser observados para asegurar la garantía del derecho a recurrir el fallo ante juez o tribunal superior.

\footnotetext{
1 Abogado (UNLP), docente del Instituto de Derechos Humanos de la Facultad de Ciencias Jurídicas y Sociales de la UNLP. E-mail: jamesvertiz@hotmail.com
} 
Al respecto señaló que, dicho derecho consiste en una garantía mínima y primordial que "se debe respetar en el marco del debido proceso legal, en aras de permitir que una sentencia adversa pueda ser revisada por un juez o tribunal distinto y de superior jerarquía", y que el mismo no puede ser efectivo si no se garantiza respecto de todo aquél que es condenado, ya que la condena es la manifestación del ejercicio del poder punitivo del Estado. Además, el derecho a recurrir el fallo es una de las garantías mínimas que tiene toda persona que es sometida a una investigación y proceso penal.

También sostuvo que el artículo 8.2.h) de la Convención se refiere a un recurso ordinario, accesible y eficaz, es decir que no debe requerir mayores complejidades que tornen ilusorio este derecho. En ese sentido, las formalidades requeridas para que el recurso sea admitido deben ser mínimas y no deben constituir un obstáculo para que cumpla con su fin de examinar y resolver los agravios sustentados por el recurrente, es decir que debe procurar resultados o respuestas al fin para el cual fue concebido. Debe entenderse que, independientemente del régimen o sistema recursivo que adopten los Estados Partes, y de la denominación que den al medio de impugnación de la sentencia condenatoria, para que éste sea eficaz debe constituir un medio adecuado para procurar la corrección de una condena errónea. Ello requiere que pueda analizar las cuestiones fácticas, probatorias y jurídicas en que se basa la sentencia impugnada, puesto que en la actividad jurisdiccional existe una interdependencia entre las determinaciones fácticas y la aplicación del derecho, de forma tal que una errónea determinación de los hechos implica una errada o indebida aplicación del derecho. Consecuentemente, las causales de procedencia del recurso deben posibilitar un control amplio de los aspectos impugnados de la sentencia condenatoria.

La importancia del cumplimento de esta obligación se funda en que existe relación entre una errónea determinación de los hechos y una indebida aplicación del derecho, por lo que la revisión que se debe hacer en cumplimiento del derecho al 
doble conforme debe permitir al juzgador realizar un control amplio de la sentencia. Este es el planteamiento que la defensa del señor Gorigoitía realizó en su escrito de recurso de casación, el cual fue rechazado "in limine" por requerir una revalorización del criterio de la Cámara Primera en materia de hechos y de valoración probatoria. En consecuencia, el Tribunal considera que la negativa por parte de la Suprema Corte de Mendoza de revisar el fondo de la cuestión planteada por la defensa del señor Gorigoitía constituyó un hecho ilícito internacional en tanto resultó en un incumplimiento del deber de revisión integral del fallo que establece el artículo 8.2.h) de la Convención.

Sobre el deber de adoptar disposiciones de derecho interno, la Corte expresó que el artículo 2 de la Convención contempla el deber general de los Estados Partes de adecuar su derecho interno a las disposiciones de la misma para garantizar los derechos en ella consagrados. Este deber implica la adopción de medidas en dos vertientes. Por una parte, la supresión de las normas y prácticas de cualquier naturaleza que entrañen violación a las garantías previstas en la Convención. Por otra, la expedición de normas y el desarrollo de prácticas conducentes a la efectiva observancia de dichas garantías. Precisamente, respecto a la adopción de dichas medidas, esta Corte ha reconocido que todas las autoridades de un Estado Parte en la Convención tienen la obligación de ejercer un control de convencionalidad, de forma tal que la interpretación y aplicación del derecho nacional sea consistente con las obligaciones internacionales del Estado en materia de derechos humanos.

De conformidad con lo antedicho, la Corte concluyó que el Estado es responsable por la violación artículo 8.2.h) de la Convención, en relación con el artículo 1.1 del mismo instrumento, debido a la falta de revisión integral de la Suprema Corte de Mendoza del recurso presentado por la defensa del señor Gorigoitía contra la sentencia condenatoria de la Cámara Primera del Crimen de Mendoza. Asimismo, concluyó que el Estado es responsable por la violación al artículo 2 de la Convención, 
como resultado de la regulación inconvencional del recurso de casación previsto en el artículo 503 de la Ley No. 1908.

III. Reparaciones: La Corte indicó que toda violación de una obligación internacional que haya producido daño comporta el deber de repararlo adecuadamente, y que esa disposición recoge una norma consuetudinaria que constituye uno de los principios fundamentales del Derecho Internacional contemporáneo sobre responsabilidad de un Estado.

Entre otras medidas reparatorias, la Corte le ordenó al Estado argentino que: a) adopte las medidas necesarias para garantizar al señor Gorigoitía el derecho de recurrir el fallo condenatorio emitido por la Cámara Primera del Crimen de Mendoza el 12 de septiembre de 1997, de conformidad con los parámetros convencionales establecidos en el artículo 8.2.h) de la Convención Americana; y, b) adopte las medidas necesarias para que los efectos jurídicos del referido fallo condenatorio, en especial lo atinente al beneficio jubilatorio y el registro de antecedentes, queden en suspenso hasta que se emita una decisión de fondo, una vez garantizado el derecho a recurrir según lo indicado en el inciso anterior.

Corte IDH. Caso Martínez Coronado Vs. Guatemala. Fondo, Reparaciones y Costas. Sentencia de 10 de mayo de 2019. Serie C No. 376

I. Hechos: El caso se relaciona con violaciones al debido proceso cometidas en el marco del proceso penal contra Manuel Martínez Coronado por el delito de asesinato de siete personas que culminó con una sentencia condenatoria a la pena de muerte, la que fue ejecutada por medio de inyección letal. De conformidad con los alegatos presentados, la utilización del elemento de peligrosidad para sustentar la responsabilidad penal incumplió con el principio de legalidad, ya que dicha figura incorpora predicciones, especulaciones y constituye una expresión del derecho penal de autor, incompatible con la Convención Americana. En particular se alegó también la violación 
del derecho a contar con los medios adecuados para la preparación de la defensa y el derecho a ser asistido por un defensor proporcionado por el Estado, así como la violación al derecho a la vida en virtud de que se aplicó la pena de muerte, pese a las violaciones al debido proceso indicadas con anterioridad.

II. Fondo: El Tribunal Interamericano examinó en el caso los alegatos relativos a la privación arbitraria de la vida y la violación al principio de legalidad; y de las garantías judiciales.

Sobre la alegada violación del derecho a la vida del señor Manuel Martínez Coronado, la Corte recordó su reiterada jurisprudencia al respecto, subrayando que la observancia del artículo 4, relacionado con el artículo 1.1 de la Convención Americana, no sólo presupone que ninguna persona sea privada de su vida arbitrariamente (obligación negativa), sino que además requiere que los Estados adopten todas las medidas apropiadas para proteger y preservar el derecho a la vida (obligación positiva), conforme al derecho de garantizar el pleno y libre ejercicio de los derechos bajo su jurisdicción . Por tal razón este artículo establece un régimen claramente restrictivo de la pena de muerte, como se infiere de la lectura de sus numerales 2, 3, 4,5 y 6 . De forma tal que esta disposición revela una inequívoca tendencia limitativa y excepcional en el ámbito de imposición y de aplicación de dicha pena.

A su vez, expresa la Corte, tal tendencia abolicionista se encuentra recogida por el Protocolo a la Convención Americana sobre Derechos Humanos relativo a la Abolición de la Pena de Muerte, que a la fecha de la presente sentencia ha sido ratificado por trece Estados de la OEA.

En el caso en concreto, se condenó a pena de muerte al señor Martínez Coronado en aplicación del segundo párrafo del artículo 132 del Código Penal guatemalteco vigente para dicha fecha, que preveía la aplicación de dicha pena "si por las circunstancias del hecho y de la ocasión, la manera de realizarlo y los móviles determinantes, se revelare una mayor y particular peligrosidad del agente". 
La Corte recordó que se había pronunciado sobre la aplicación del referido artículo 132 del Código Penal y el concepto de "peligrosidad futura" en el caso "Fermín Ramírez Vs. Guatemala" en donde declaró que la referida norma era contraria a la Convención Americana, particularmente por cuanto violaba el artículo 9 de la Convención, por lo que ordenó se adecue dicha norma al derecho internacional de los derechos humanos.

En la misma sentencia también expresó que el principio de legalidad es uno de los elementos centrales de la persecución penal en una sociedad democrática. Al establecer que 'nadie puede ser condenado por acciones u omisiones que en el momento de cometerse no fueran delictivos según el derecho aplicable', el artículo 9 de la Convención obliga a los Estados a definir esas "acciones u omisiones" delictivas en la forma más clara y precisa posible.

De modo que, si la peligrosidad del agente trae consigo una consecuencia penal de tan grave naturaleza, como ocurre en la hipótesis de Asesinato, conforme a la ley guatemalteca, las circunstancias personales del agente deberían formar parte de la acusación, quedar demostradas durante el juicio y ser analizadas en la sentencia.

Por lo que, en concepto de la Corte, el problema que plantea la invocación de la peligrosidad no sólo puede ser analizado a la luz de las garantías del debido proceso, dentro del artículo 8 de la Convención. Esa invocación tiene mayor alcance y gravedad. En efecto, constituye claramente una expresión del ejercicio del ius puniendi estatal sobre la base de las características personales del agente y no del hecho cometido, es decir, sustituye el Derecho Penal de acto o de hecho, propio del sistema penal de una sociedad democrática, por el Derecho Penal de autor, que abre la puerta al autoritarismo precisamente en una materia en la que se hallan en juego los bienes jurídicos de mayor jerarquía.

Ello así, puesto que, la valoración de la peligrosidad del agente implica la apreciación del juzgador acerca de las 
probabilidades de que el imputado cometa hechos delictuosos en el futuro, es decir, agrega a la imputación por los hechos realizados, la previsión de hechos futuros que probablemente ocurrirán. En consecuencia, la introducción en el texto penal de la peligrosidad del agente como criterio para la calificación típica de los hechos y la aplicación de ciertas sanciones, es incompatible con el principio de legalidad criminal y, por ende, contrario a la Convención.

En ese sentido, el empleo del criterio de peligrosidad del agente, tanto en la tipificación de los hechos del ilícito penal cometido por el señor Martínez Coronado, como en la determinación de la sanción correspondiente, resulta incompatible con el principio de legalidad previsto en la Convención Americana. El examen de la peligrosidad del agente implica la valoración por parte del juzgador de hechos que no han ocurrido $\mathrm{y}$, por lo tanto, supone una sanción basada en un juicio sobre la personalidad del infractor y no en los hechos delictivos imputados conforme la tipificación penal aplicable.

En el caso concreto, dada la aplicación de la pena de muerte impuesta con base en una norma contraria a la Convención Americana, el Tribunal consideró que el Estado es responsable de la vulneración de los artículos 4.1 y 4.2 de la Convención, en relación con el artículo 1.1 del mismo instrumento.

Concluyendo que, la vulneración del principio de legalidad en el presente caso se encuentra configurada por dos elementos: a) la indeterminación del concepto de "peligrosidad futura" contenido en el artículo 132 del Código Penal, y b) la aplicación al señor Martínez Coronado de la sanción prevista (la pena de muerte) en dicha disposición.

Respecto de las garantías del debido proceso, y en particular sobre el derecho a la defensa de oficio, el Tribunal destacó "la importancia fundamental que tiene el servicio de asistencia letrada gratuita para la promoción y protección del derecho de acceso a la justicia de todas las personas, en particular de aquellas que se encuentran en una situación especial de vulnerabilidad". 
La institución de la defensa pública, a través de la provisión de servicios públicos y gratuitos de asistencia jurídica permite, sin duda, compensar adecuadamente la desigualdad procesal en la que se encuentran las personas que se enfrentan al poder punitivo del Estado, así como la situación de vulnerabilidad de las personas privadas de libertad, y garantizarles un acceso efectivo a la justicia en términos igualitarios.

No obstante, la Corte ha considerado que nombrar a un defensor de oficio con el sólo objeto de cumplir con una formalidad procesal equivaldría a no contar con defensa técnica, por lo que es imperante que dicho defensor actúe de manera diligente con el fin de proteger las garantías procesales del acusado y evite así que sus derechos se vean lesionados y se quebrante la relación de confianza. A tal fin, es necesario que la institución de la defensa pública, como medio a través del cual el Estado garantiza el derecho irrenunciable de todo inculpado de delito de ser asistido por un defensor, sea dotada de garantías suficientes para su actuación eficiente y en igualdad de armas con el poder persecutorio. La Corte ha reconocido que para cumplir con este cometido el Estado debe adoptar todas las medidas adecuadas. Entre ellas, contar con defensores idóneos y capacitados que puedan actuar con autonomía funcional.

Invocando su jurisprudencia del caso "Ruano Torres vs. Guatemala" también sostuvo que el derecho de defensa implica que está sea eficaz, oportuna, realizada por personal técnico, que permita fortalecer la protección del interés concreto del imputado y no como un simple medio para cumplir formalmente con la legitimidad del proceso. Por ende, cualquier forma de defensa aparente resultaría violatoria de la Convención Americana. En esta línea, "la relación de confianza debe ser resguardada en todo lo posible dentro de los sistemas de defensa pública por lo que deben existir mecanismos ágiles para que el imputado pueda pedir que se evalúe el nivel de su defensa y ningún defensor público puede subordinar los intereses de su defendido a otros intereses sociales o institucionales o a la preservación de la justicia. 
Ahora, en el presente caso, la discusión jurídica a analizar se centró en la compatibilidad con la Convención, y particularmente, con el derecho a la defensa del señor Martínez Coronado, de que el Estado le haya proporcionado una defensa común de oficio a la presunta víctima y a otro co-imputado, ya que según lo alegado por la Comisión y los representantes, la defensa común de oficio pareciera haber tenido una incidencia negativa a los intereses del señor Martínez.

Como punto de partida la Corte constató que en el derecho penal guatemalteco la defensa común de los imputados tanto si es provista por sus abogados de confianza o por aquellos designados por el Estado a través de la defensa pública está prohibida y, solo se permite excepcionalmente en caso de que no exista manifiesta incompatibilidad.

En tal sentido, señaló que correspondería al Estado, mediante las autoridades competentes, identificar si existen dichas incompatibilidades y adoptar las medidas conducentes para que se garantice el derecho a la defensa de los co-imputados involucrados. Este principio es especialmente relevante en casos donde los imputados puedan enfrentar una condena severa, como es la pena de muerte. Por otra parte, la existencia de inconsistencias en las declaraciones realizadas por los co-imputados en el marco de un proceso penal no demuestra necesariamente una incompatibilidad en sus defensas e intereses que impida una defensa común.

No obstante, en el caso concreto la contradicción existente en las declaraciones de los co-imputados recae sobre elementos sustanciales de la versión de los hechos propuesta por el señor Martínez Coronado, de forma tal que la contradicción le privó de un elemento sustancial de su defensa. En efecto, en la sentencia de primera instancia se hace alusión a que el señor Martínez Coronado afirma que el co-imputado le informó a la una de la mañana que había escuchado disparos, razón por la cual acudió al lugar de los hechos, mientras que por su parte DA negó tales hechos y afirmó que se enteró de los homicidios a las seis 
de la mañana. En esa medida, en este caso las inconsistencias en las declaraciones por parte de los co-imputados debieron ser advertidas por la defensa común, quien debió ponerlas en conocimiento del tribunal para efectos de que se nombrara otro defensor, o incluso las autoridades judiciales encargadas de dirigir el proceso debieron adoptar de oficio las medidas pertinentes para garantizar el derecho a la defensa por tratarse de una defensa pública proporcionada por el Estado. En razón de lo anterior, la Corte concluye que el Estado incumplió con su deber de asegurar el derecho irrenunciable de ser asistido por un defensor proporcionado por el Estado que le garantizara al inculpado los medios adecuados para su defensa, en violación de los artículos 8.2.c) y 8.2.e) de la Convención Americana, en la medida que la defensa común, vulneró los derechos del señor Martínez Coronado.

III. Reparaciones: El Tribunal indicó que toda violación de una obligación internacional que haya producido daño comporta el deber de repararlo adecuadamente, y que esa disposición recoge una norma consuetudinaria que constituye uno de los principios fundamentales del Derecho Internacional contemporáneo sobre responsabilidad de un Estado.

Además de otorgar medidas de reparación económicas, la Corte ordenó en carácter de medidas de satisfacción, que se publique en el plazo de seis meses: a) el resumen oficial de esta Sentencia elaborado por la Corte, por una sola vez, en el Diario Oficial en un tamaño de letra legible y adecuado; b) el resumen oficial de la Sentencia elaborado por la Corte, por una sola vez, en un diario de amplia circulación nacional en un tamaño de letra legible y adecuado, y c) la presente sentencia en su integridad, este disponible por un período de un año, en un sitio web oficial, de manera accesible al público. 